\title{
Development of New Elements of Precision Farming Systems Based on Precision Farming Centre of Russian State Agrarian University - Moscow Agricultural Academy Named after K. A. Timiryazev.
}

\author{
Viktor Balabanov* \\ Russian Federation, Russia
}

*Corresponding author: Viktor Balabanov, Doctor of Technical Sciences, Professor, Russian Federation, Russia.

Received Date: October 09, 2018

Published Date: November 13, 2018

\begin{abstract}
The paper presents information on development and branches of activities of Precision Farming Centre of Russian State Agrarian University- Moscow Agricultural Academy named after K. A. Timiryazev. Currently, a comprehensive analysis of problems connected with implementation of precision farming systems in the Russian Federation is carried out. The paper describes the precision farming system design and service specialist training programs. The paper also contains the history of the creation and principal characteristics of the Green Bot agrotechnical mobile robotic complex developed on the basis of joint theoretical and empirical research in the field of agricultural work automation and robotization with the application of information and navigation technologies in Russian State Agrarian University named after K. A. Timiryazev in collaboration with "Cosmos Complect" Ltd.
\end{abstract}

Keywords: Agrotechnical robotic complex; Greenbot; Navigation technologies; Closed soil systems

\section{Introduction}

Educational-scientific center for precision farming was opened in 2007 on the basis of the experimental field of the Russian state agrarian University- MTAA named after K. A. Timiryazev in the framework of implementation of innovative educational programs for the organization and realization of educational, research and development of innovative activities on the basis of use of modern agricultural technologies. Long-term research results in the field experience of the scientific center of precision agriculture demonstrated the advantage of the separate elements of precision agriculture technologies, in particular of crop and landings of agricultural crops, potato cultivation, fertilizer winter wheat and use of herbicides; definitions of nutrient content in the soil; creation of electronic maps. For example, it was found that the use of technology "precision farming" can reduce by $25-30 \%$ of mineral fertilizers and means of plant protection. Currently, the most advanced technology that is given attention is the use of unmanned aerial vehicles (UAVs) and the development of robotic systems for agricultural purposes. The use of UAVs allows you to quickly and efficiently make an inventory of agricultural lands; creation of field maps for the assessment of their cadastral value; the preparation of orthophotos surface; to calculate the standardized index of vegetation biomass and other indicators, as well as to carry out various types of control and management of agricultural machinery.

The technology used today in most Russian households, is significantly outdated, and the new progressive methods, successfully applied in the world, has not yet received enough attention and development in our country. However, the food security of Russia without advanced approaches impossible.

The problem of reforming the Russian agrarian sector are especially relevant today. The introduction of new high-tech methods of agriculture, which not only contribute to the improvement of soil fertility and obtaining stable yields at optimal costs, but also help the entire agri-food sector to access new innovative way of development, is necessary. Without this, food security of Russia will be impossible.

One of the catalysts of innovation processes and the accelerated development of many industries serve as navigation technologies on the basis of domestic global navigation satellite system (GNSS) GLONASS. They are actively employing for management of different resources regions of the country, including agro-industrial complex. 
Recently in world agriculture on the basis of the navigation technologies (largely based on the development of accurate technologies (coordinate) of agriculture) has formed a new scientific and practical direction of management - precision agroculture (precision agriculture), or precision farming (precision farming).

This type of agriculture and General agriculture became possible with the development of means of communication, GNSS-GPS/GLONASS, computerization and use of navigation and information technologies in automation of agricultural production.

\section{Accurate Management}

In accordance with GOST R 56084-2014, coordinate (exact) agriculture is a combination of hardware, software and hardware systems, navigation, geoinformation and communication technologies, allowing to capture, process and apply the information that is tied to coordinates, with the purpose of optimization of agrotechnological solutions to the crop production.

The main difference from the traditional concept of management is that precision farming is tied to a specific navigation coordinates and consider as a unit of account, for example, not all the field as a whole and each individual (comparable to the accuracy of global positioning) plot with values of its topography, fertility, plant composition and other characteristics. Based on the collected and processed data, this concept involves the use in each of the sections is strictly defined and justified agrotechnological techniques of growing specific crops.

Coordinate agriculture is one of the modern trends in the development of conservation agriculture. Its essence- the integrated process control plant growth in accordance with their needs. The strategy of using technology to coordinate agriculture aims to attract and to use the maximum information for developing agrotechnological solutions and their optimization in relation to specific soil and climatic and economic conditions (within fields) and the differential implementation of the basic technological operations for maximum quantitative and qualitative indicators.

In other words, the coordinate agriculture provides improved field condition and efficiency of agromenedzhment. While implementing a number of basic principles: agronomic (taking into account the real needs of the crop fertilizer, thus not only improving agricultural production, but also maintained the soil fertility of the fields); technological (manufactured products are of higher quality); technical (reduced time management at farm level, including improved planning of agricultural operations); ecological (decreasing the harmful effects of agricultural production on the environment, for example, more accurate estimation of crop demand in nitrogen leads to restrictions on the use of nitrogen fertilizers) and economic (the rise in productivity and/or cost reduction, which increases the efficiency of agribusiness).

Another advantage of the use of technology coordinate agriculture to agribusiness is the maintenance of digital libraries and subsequent storage history of field work and harvest, which is important for planning and decision-making on crop rotation, and to complete necessary reporting of the production cycle.

All these activities are ultimately aimed at getting this field (array) the maximum number of high-quality and cheapest products.
For all plants in this array are created the same conditions of growth and development without violating the environmental legislation, and the very coordinate agriculture is being implemented through the gradual development of agricultural technologies based on a fundamentally new, highly efficient and environmentally friendly technical and agrochemical means.

\section{Field Experience}

Educational-scientific Centre for precision farming was opened in 2007 on the basis of Field experimental station of Russian state agrarian University- MTAA named after K. A. Timiryazev (RGAU-MSHA named after K. A. Timiryazev) in the framework of the implementation of the educational program "Formation of innovative educational environment for training of a new generation of the specialists of agricultural profile." The main goal of this project is the organization and implementation of training, research innovative activities through the use of modern agricultural technologies and principles coordinate (precision) agriculture.

At this stage, to study agroecological efficiency of precision agriculture technology in the experimental field of the University laid the stationary field experiment with a total area of about 6 hectares, which demonstrates the two technologies of cultivation of agricultural crops, for example potatoes, winter wheat and triticale, spring barley and annual grasses. Thus, compared a traditional system and a system based on the principles of precision farming with the use of navigation technologies.

The main objective of precision agriculture Centre, Russian state agrarian University-MTAA named after K. A. Timiryazev teaching students the technologies of coordinate (precision) agriculture. However, in addition, much attention is paid to professional development of teaching staff and specialists of agricultural enterprises. Also introduced elements of coordinate technologies (precision) farming, developed by scientists of the University. Thanks to advanced agricultural technologies in the field of adaptive-landscape farming popularized and transferred to interested farmers.

For the preparation of graduates for professional activities in the field coordinate (exact) agriculture (which includes the organization of mechanized operations, agronomic research and development aimed at solving complex tasks for the production of high quality crop production through the application of geoinformation and navigation technologies in modern agriculture) for the first time in Russia at the Department "Technologies and cars in plant growing", Russian state agrarian University-MTAA named after K. A. Timiryazeva in 2014 was opened by the inter-faculty master program "Technology and machines coordinate farming".

Training in this program is aimed at training highly qualified specialists and consultants that will be engaged in managerial, analytical, information and consulting and research work.

The training program includes the study of technologies and machines for the coordinate (exact) agriculture; agro-ecological assessment of land and design of agricultural technologies based on geoinformation and navigation systems for different organizational forms of agriculture and their development; methods of remote monitoring of production processes and management of agricultur- 
al plants, as well as differential application of fertilizers and plant protection means.

One of the main tasks is the development of innovative solutions for restructuring and the improvement of the economic work in state, regional, municipal, agricultural enterprises of various levels on the basis of application of modern geoinformation and navigation technologies.

Along with this the center conducted studies on the development of agrotechnics (high-yielding varieties of field crops), and ways of energy saving and conservation of soil treatment, effective methods of crop planting, maintenance and harvesting, using modern widespan vehicles equipped with navigation systems. In addition, there is the development of highly efficient environmentally friendly systems of plant protection from pests, diseases and weeds. All these areas will allow you to perform term papers, theses, final qualifying works and master's thesis students and graduate students of various faculties of the University.

Many years of research results in the field experience CTS Russian state agrarian University-MTAA named after K. A. Timiryazev demonstrated the advantage of separate elements of technology of precision farming, in particular, sowing and planting agricultural crops, grebliauskiene in the cultivation of potatoes, carrying out dressing of winter wheat, application of herbicides in crops, indirect determination of the content of nutrients in the soil with the preparation of electronic maps of crop yield. For example, it was found that the consumption of pesticides and the working solution when using precision farming technology is reduced by $25-30 \%$, and savings of fertilizers is on average $20-30 \%$.

Currently, the most advanced technology, which in RSAU MAA named after K.A. Timiryazev is given attention is the use of unmanned aerial vehicles (UAVs) and the development of robotic systems for agricultural purposes.

The use of UAVs allows you to quickly and effectively inventory agricultural land; to create maps of fields to assess their cadastral value; to build orthophotos of the surface of the field; to monitor the state of the fallow fields and agricultural crops; to calculate the standardized index of vegetation biomass (NDVI) and other vegetative indices, as well as to implement various kinds of control and management of agrotechnical actions.

Research on the use of UAVs is conducted in RSAU-MAA named after K.A. Timiryazev in collaboration with Russian group of companies "GEOSCAN", which manufactures and supplies unmanned aerial systems (AFC), photogrammetric software Agisoft Photoscan and software visualization and data analysis of aerial photography.

So, using the complex of "GEOSCAN 201" with two cameras on Board area of 1 thousand hectares it is possible to capture in just 40 minutes and provide the necessary information to the operators (agronomists, farm managers) to assess the status and operational land management decisions. In particular, images with triple overlapping the entire area of the Field experimental station of the Academy in 49 hectares AFK "GEOSCAN 101" took only about 20 minutes.

Another innovative aspect is studied at the faculty of "Processes and machines in agribusiness" RSAU - MAA named after K.A. Timiryazev - the use of robotic systems in agriculture, including working on the basis of technology "agrovision".

Studies are underway in conjunction with the company AMAZONEN-Werke H. Dreyer GmbH \& Co. KG (Germany), which produces the prototype of Autonomous field robot Boni Rob in cooperation with Bosch and "Cosmos Complect" Ltd. (Russia), and others. Robotic systems are currently already being partially applied in various branches of agriculture, such as harvesting, introduction of crop protection agents and agrochemicals, weeding, irrigation, sheep shearing, milking cows, etc.

Based on long theoretical and practical research in the field of automation of agricultural operations with the use of navigation technologies, including on the basis of the Russian global navigation satellite system GLONAAS, at the Russian State Agrarian University, the MAAA named after K.A. Timiryazev developed a concept and a sketch of the agrotechnical mobile robotic complex-Green Bot (Figure 1) [1-6].

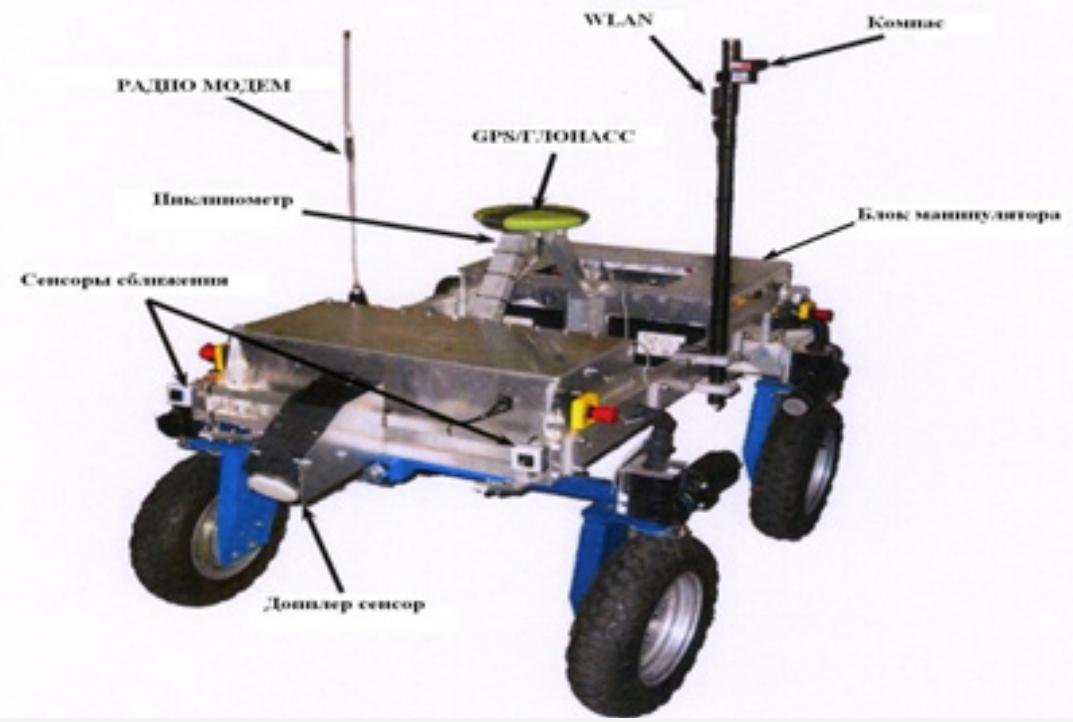

Figure 1: The outline of the agro-technological robotic complex Green Bot. 
Green Bot is a standalone mobile robot, consisting of a platform and a probe-sensor system. The platform provides its universal functions - common on-board control, moving along RFID tags or GPS / GLONASS coordinates, powering all subsystems with the ability to recharge at fixed positions, reading, processing and storing information from sensors, managing a universal manipulator, supporting information and communication channels, provision of auto-diagnostics and alarm.

The probe-sensor system presents for this version of the robot a set of six modules based on the "system in the body" technology, which simply connects to the platform using a standard mechanical interface: environmental data collection, soil analysis, loosening, watering, laser weeding, harvesting.

All modules have a unified CAN interface. To the universal manipulator with a unified fastening, you can connect tools for loosening, laser weeding and watering. GREEBOT is powered by rechargeable batteries and recharges them independently from a $220 \mathrm{~V} / 50 \mathrm{~Hz}$ source, which it finds at a predetermined position.

Between the robots on one site there is a data exchange. Communication with the robot is carried out using a PC, where all the data generated by the robot accumulates. Simply unqualified personnel using the appropriate spare parts after receiving a diagnostic message carry out replacement of blocks or modules during operation.

All modules of the sensor-sensor system are made in the form of nodes with a unified mechanical interface for quick connection to the manipulator or platform. In all modules and subsystems of the platform, a CAN interface is used.

To the universal manipulator as a unified connection it is possible to connect tools for loosening, laser weeding and watering.

Development is the winner of the competition of innovative projects of the International Exhibition of Agricultural Machinery AGROSALON-2016 (Crocus Expo, Moscow).

At the first stage, the Green Bot agrotechnical robotic complex will be most effective for use in closed soil systems: greenhouses, greenhouses, winter gardens, as well as for gas detection systems, including for lawns of sports facilities.
Domestic, as well as the whole world's agriculture is still lagging behind in the application of robots in comparison with other sectors of the economy, so research in this direction will be every year to develop more and more rapidly.

\section{Conclusion}

In the paper we have considered the fundamental problems of organization of Precision farming center of RGAU-MSHA named after K. A. Timiryazev. We have described the primary objectives of the Centre. A description of the Green Bot agrotechnical mobile robotic complex created within the framework of the Centre has been given, and its availabilities in precision farming systems have been specified. We have made a decision regarding application of precision farming systems in agriculture in Russia.

\section{Acknowledgement}

None.

\section{Conflict of Interest}

No Conflict of Interest.

\section{References}

1. Balabanov VI (2016) Field strategy. Implementation of innovations in agriculture coordinate. Farming equipment and technology 5: 50-53.

2. Boutin VM, Balabanov VI, Berezovsky EV (2012) // Smart frames for "smart farm" // Bulletin of GLONASS 1: 41-44.

3. VI Balabanov, VF Fedorenko, et al (2016) Technology, machines and equipment for the coordinate (exact) Agriculture: Proc. /: FGBNU "Rosinformagroteh", 240 p.

4. Shulga EF, Kupriyanov AO, Khlyustov VK, Balabanov VI, Zeiliger AM (2016) Agricultural enterprise management using space-based navigation aids (GLONASS) and remote sensing: Monograph / The edition -in RGAU -MSKHA, pp. 286

5. Balabanov VI, Zhelezova SV, Berezovsky EV, Belenkov AI, Egorov VVM (2013) Navigation systems in agriculture. Coordinate agriculture. [Tutorial]. Because of RGAU- Timiryazev MAA, pp. 143.

6. Balabanov VI, Berezovsky EV (2011) Precision agriculture technology and the experience of their application in the Russian State Agrarian University named after K.A. Timiryazev // Herald GLONASS, 2: 56-68. 